\title{
Female breast cancer survival in Qidong, China, 1972-2011: a population-based study
}

\author{
Jian Zhu' ${ }^{1}$ Jian-Guo Chen ${ }^{1,2^{*}}$, Yong-Sheng Chen ${ }^{1}$, Yong-Hui Zhang ${ }^{1}$, Lu-Lu Ding ${ }^{1}$ and Tao-Yang Chen ${ }^{1}$
}

\begin{abstract}
Background: Based on data from the population-based Qidong Cancer Registry, we report a survival analysis for female breast cancer patients diagnosed during 1972-2011 in order to assess the long-term trends for the prognosis of this cancer.

Methods: The last follow-up for survival status of the 3,398 registered female breast cancer cases was April, 2012. Cumulative observed survival (OS) and relative survival (RS) rates were calculated using Hakulinen's method performed by the SURV3.01 Software developed at the Finnish Cancer Registry.

Results: The one-, three-, five-, ten-, fifteen-, twenty-, thirty-, and forty-year OS rates were $83.61 \%, 67.53 \%, 58.75 \%$, $48.56 \%, 42.57 \%, 38.30 \%, 29.19 \%, 19.35 \%$; and the RS rates were $84.76 \%, 70.45 \%, 63.12 \%, 56.81 \%, 55.26 \%, 56.36 \%, 62.59 \%$, $84.00 \%$, respectively. Five-year RS rates of age groups $15-34,35-44,45-54,55-64,65-74$, and $75+$ were $60.17 \%$, $68.27 \%, 67.79 \%, 56.03 \%, 55.50 \%$, and $57.28 \%$; 10 -year RS rates were $54.16 \%, 59.59 \%, 61.34 \%, 47.78 \%, 51.30 \%$, and $59.28 \%$, respectively. There were statistical differences among the age groups (RS: $x^{2}=152.15, P=0.000$ ). Remarkable improvement could be seen for the 5-year RS rates from 52.08\% in 1972 to 69.26\% in 2003-2007, and the 10-year RS rates from $43.16 \%$ in 1972 to $60.85 \%$ in $1998-2002$, respectively.
\end{abstract}

Conclusions: Survival outcomes from Qidong registered cases with breast cancer have shown gradual progress during the past 40 years. The disparities between survival rates of this area and developed countries are getting narrower, but there is still great need for improving survival in Qidong.

Keywords: Breast cancer, Cancer registration, Observed survival, Relative survival, Qidong

\section{Background}

This study was based on the data of the Qidong Cancer Registry (QCR), a population-based cancer registry, which was established in 1972 and is administered by the Qidong Liver Cancer Institute (QDLCI). The QCR covers Qidong City, Jiangsu Province, China with an area of $1208 \mathrm{~km}^{2}$, and a population of $1.12 \mathrm{M}$ at the end of 2011. Geographically, Qidong is located at the mouth of the Yangtze River (Chang Jiang), by the Yellow Sea (Huang Hai). The QCR is one of the longest standing cancer registries in China. In 1974, the QDLCI established an all-death cause registration system (as an official Vital Statistics source) in the same coverage area for disease monitoring.

\footnotetext{
* Correspondence: chenjg@vip.sina.com

'Qidong Liver Cancer Institute, Qidong Cancer Registry, Qidong People's Hospital, Qidong 226200, China

${ }^{2}$ Nantong University Tumor Hospital/Institute, School of Public Health, Nantong University Tum
}

\section{Biomed Central}

(c) 2014 Zhu et al.; licensee BioMed Central Ltd. This is an Open Access article distributed under the terms of the Creative Commons Attribution License (http://creativecommons.org/licenses/by/2.0), which permits unrestricted use, distribution, and reproduction in any medium, provided the original work is properly credited. The Creative Commons Public Domain Dedication waiver (http://creativecommons.org/publicdomain/zero/1.0/) applies to the data made available in this article, unless otherwise stated.
Breast cancer is now the most common cancer in females all over the world [1,2]. With the development of the economy and the improvement of living standards, the incidence of breast cancer is increasing year by year in China [3]. In Qidong, breast cancer has been the fourth most common cancer in females over the past 40 years, with an aggregate crude incidence rate of 14.94 per 100000 , accounting for $9.95 \%$ of all cancer sites combined in women. The annual percentage change (APC) of the world age-standardized incidence rate between 1972 and 2011 was 1.31\%, with a rapid increase during the latter stages of the past four decades [4]. Thus, further research on breast cancer etiology, prevention and treatment hence is necessary.

This study presents current survival data and their trends during the period of 1972-2011. The data collected over this long-term period and the results accurately derived from them reflect a profile for the prevalence and 
management of female breast cancer in Qidong. This information on survival provides clinicians and researchers with opportunities to explore breast cancer trends, to measure progress against breast cancer, and to examine implications for breast cancer control in the context of associations with risk factors, prevention interventions, and the dissemination of advances in treatment.

\section{Methods}

The data in this study are from the QCR, which at its founding was designated as the cancer registration repository by the local health authority with compulsory reporting by health care workers. Several years later cancer registration was mandated to be compulsory by the provincial health authority. Now this cancer registry is a member of the national monitoring program (or the National Cancer Registration Network) [5,6] of the National Central Cancer Registries of China supported by the Ministry of Finance and the Ministry of Health of China: Tumor Follow-up Registration Programs (MF2008-293, 2009-193, and 2010-90).

The Qidong All-death Cause Registration System has been an official vital statistics source approved by the Ministry of Health of China since 1974 [7], with death from any cause reported by death certification notifications (DCN). Meeting International Agency for Research on Cancer/International Association of Cancer Registries (IARC/IACR) standards for quality, completeness, timeliness and unresolved duplicate records, the QCR is a member of the IACR. QCR data have been included in "Cancer Incidence in Five Continents" (CI5) [8,9] and other publications [10-13]. The data reliability has earned recognition in domestic and international studies $[10,12,14]$. For the use of these cancer statistics, there is no further need for approval by an Institutional Review Board and no need for informed consent from any of the patients involved.

The QCR uses both active and passive methods for cancer data collection. All data files received from lower-level registries and all other hospitals are checked with cancer report lists and DCNs in order to track down missing cases and to exclude duplicate registrations. At present, there are 12 town-level registries, each with one full-time or part-time health worker doing the registration and collection of DCNs. All new cancer patients in the catchment area are therefore registered, checked, and then reported to the QCR. When the patient dies, whether at home or in hospital, the registration official adds the date of death to the record, and reports it again, together with a DCN card. If the registry personnel receive the death notification first, the patient's medical records are reviewed or a home visit is carried out to obtain further information. Hence, the collection of high-quality follow-up data has been possible in Qidong [10,11].
According to Union for International Cancer Control (UICC), breast cancer refers to the malignant tumor originating in the mammary gland epithelial tissue. In QCR, cancer cases were classified and coded according to the International Classification of Diseases, the $10^{\text {th }}$ revision (ICD-10), and the International Classification of Diseases for Oncology $3^{\text {rd }}$ edition [15] as well. This study included all patients with female breast cancer reported to the QCR from 1972 to 2011; codes of ICD-10 C50.0-C50.9 and topography codes C50.0-C50.9 of ICD-O-3 with behaviour codes 3 were included. Excluded were all death certificate-only, autopsy, and individual cases with malignant secondary (metastatic to the breast), benign, in situ and uncertain or unknown diagnosis.

A total of 3,452 cases with breast cancer were registered from January 1, 1972 to December 31, 2011. Fifty-four (1.56\%) male breast cancer cases were excluded, hence 3,398 female breast cancers were included for analysis. The deadline for the last follow-up for survival status was April, 2012. The proportion of cases with morphological verification was $93.11 \%(3,164 / 3,398)$, with no breast cancer cases recognized by death certificate only. The survival duration of each case was determined as the time difference from the date of initial diagnosis to the date of death due to breast cancer $(1,687 / 3,398=49.65 \%)$, date of death due to other diseases $(3 / 3,398=0.09 \%)$, date of loss to follow-up $(381 / 3,398=11.21 \%)$, and the closing date for those still alive $(1,327 / 3,398=39.05 \%)$.

Cumulative observed survival (OS) and relative survival (RS) rates were calculated. RS was defined as the ratio of the OS rate to the expected rate, which was estimated from the general gender and calendar period-specific life tables for Qidong residents according to Hakulinen's method [16]. The survival experience of patients were adjusted for normal life expectancy of the general population of the same age, which makes RS rate an estimate of the chance of surviving the effects of cancer [17]. The OS and RS rates were computed within six age groups (15-34, 35-44, 45-54, 55-64, 65-74, 75+) and nine calendar periods (1972, 1973-1977, 1978-1982, 1983-1987, 1988-1992, 1993-1997, 1998-2002, 20032007, 2008-2011), using Hakulinen's method performed by the SURV3.01 software developed at the Finnish Cancer Registry [18]. Survival trends could be shown through comparing different calendar periods. Statistical tests are included in this software. Relative rates among different age groups were tested using $\mathrm{H}_{0}-\mathrm{H}_{2}$ equal vs. unequal hazards tests.

\section{Results}

\section{Observed survival and relative survival rates}

Table 1 shows OS and RS rates by the survival year. The one-, three-, five-, ten-, fifteen, twenty, thirty, and forty-year OS rates of female breast cancer in Qidong during 
Table 1 Observed survival (OS) and relative survival (RS) rates of female breast cancer in Qidong, 1972-2011 (\%)

\begin{tabular}{|c|c|c|c|c|}
\hline Survival year & OS & $2 * \mathrm{SE}_{\mathrm{OS}}$ & RS & $2 * \mathrm{SE}_{\mathrm{RS}}$ \\
\hline 1 & 83.61 & 1.29 & 84.76 & 1.31 \\
\hline 2 & 74.12 & 1.55 & 76.22 & 1.59 \\
\hline 3 & 67.53 & 1.68 & 70.45 & 1.75 \\
\hline 4 & 62.41 & 1.76 & 66.06 & 1.87 \\
\hline 5 & 58.75 & 1.81 & 63.12 & 1.95 \\
\hline 6 & 56.04 & 1.85 & 61.16 & 2.02 \\
\hline 7 & 53.20 & 1.89 & 59.00 & 2.09 \\
\hline 8 & 51.58 & 1.91 & 58.18 & 2.16 \\
\hline 9 & 50.07 & 1.93 & 57.49 & 2.22 \\
\hline 10 & 48.56 & 1.96 & 56.81 & 2.29 \\
\hline 11 & 47.35 & 1.98 & 56.49 & 2.36 \\
\hline 12 & 45.71 & 2.01 & 55.64 & 2.44 \\
\hline 13 & 45.06 & 2.02 & 55.98 & 2.51 \\
\hline 14 & 43.75 & 2.05 & 55.53 & 2.60 \\
\hline 15 & 42.57 & 2.08 & 55.26 & 2.70 \\
\hline 16 & 41.48 & 2.10 & 55.11 & 2.80 \\
\hline 17 & 40.49 & 2.13 & 55.10 & 2.90 \\
\hline 18 & 39.53 & 2.16 & 55.16 & 3.01 \\
\hline 19 & 39.26 & 2.17 & 56.22 & 3.10 \\
\hline 20 & 38.30 & 2.20 & 56.36 & 3.23 \\
\hline 21 & 37.35 & 2.23 & 56.58 & 3.38 \\
\hline 22 & 36.63 & 2.26 & 57.23 & 3.54 \\
\hline 23 & 36.38 & 2.28 & 58.69 & 3.67 \\
\hline 24 & 35.27 & 2.34 & 58.86 & 3.90 \\
\hline 25 & 34.20 & 2.40 & 59.15 & 4.16 \\
\hline 26 & 33.85 & 2.43 & 60.80 & 4.36 \\
\hline 27 & 32.89 & 2.51 & 61.49 & 4.69 \\
\hline 28 & 31.18 & 2.65 & 60.85 & 5.18 \\
\hline 29 & 30.24 & 2.73 & 61.77 & 5.59 \\
\hline 30 & 29.19 & 2.83 & 62.59 & 6.07 \\
\hline 31 & 29.19 & 2.83 & 65.82 & 6.39 \\
\hline 32 & 27.54 & 3.03 & 65.42 & 7.20 \\
\hline 33 & 26.41 & 3.18 & 66.47 & 8.00 \\
\hline 34 & 25.95 & 3.26 & 69.66 & 8.74 \\
\hline 35 & 24.16 & 3.63 & 69.47 & 10.43 \\
\hline 36 & 24.16 & 3.63 & 74.70 & 11.22 \\
\hline 37 & 23.23 & 3.94 & 77.82 & 13.19 \\
\hline 38 & 20.96 & 4.68 & 76.35 & 17.04 \\
\hline 39 & 19.35 & 5.31 & 76.90 & 21.12 \\
\hline 40 & 19.35 & 5.31 & 84.00 & 23.07 \\
\hline
\end{tabular}

$2 * S E_{O S}$, Twice standard error of $\mathrm{OS} ; 2 * S E_{R S}$, Twice standard error of RS.
1972-2011 were $83.61 \%, 67.53 \%, 58.75 \%, 48.56 \%$, $42.57 \%, 38.30 \%, 29.19 \%$, and $19.35 \%$, while the RS rates were $84.76 \%, 70.45 \%, 63.12 \%, 56.81 \%, 55.26 \%$, $56.36 \%, 62.59 \%$, and $84.00 \%$, respectively. Figure 1 indicates OS and RS trends of female breast cancer in Qidong during $1972-2011$ by the survival year. Significant disparities between OS and RS rates could be found in female breast cancer patients surviving over 10 years. For survivors more than 20 years after diagnosis, RS rates increased with the survival year, implying that these women with breast cancer have a relatively higher survival chance compared to the general population with the same demographical characteristics.

\section{Survival rate by age group}

Table 2 shows the 5-, and 10-year OS and RS rates by age group. The 5-year OS rates of age groups 15-34, $35-44,45-54,55-64,65-74$, and $75+$ were $59.81 \%$, $67.42 \%, 66.26 \%, 53.44 \%, 47.82 \%$, and $30.42 \%$, while the 10 -year OS rates were $53.36 \%, 57.82 \%, 58.09 \%, 42.11 \%$, $32.05 \%$, and $14.78 \%$, respectively. The 5 -year RS rates were $60.17 \% 68.27 \%, 67.79 \%, 56.03 \%, 55.50 \%$, and $55.28 \%$, and 10 -year RS rates were $54.16 \%, 59.59 \%, 61.34 \%, 47.78 \%$, $51.30 \%, 59.28 \%$, respectively. The patients at $35-44$ or 45-54 years of age experienced higher 5-, and 10-year OS and RS rates. Statistical differences could be found among the different age groups (RS: $X^{2}=152.15, P=0.000$ ).

\section{Survival rate by period}

Table 3 shows the RS rates by survival year and by period. An increasing trend for the RS rates of female breast cancer could be observed through the nine intervals during 1972-2011 period. Remarkable improvement could be seen for the 5-year RS rates of 52.08\% in 1972 to that of $69.26 \%$ in 2003-2007, and for the 10-year RS rates of $43.16 \%$ in 1972 to that of $60.85 \%$ in 1998-2002. Little improvement was observed for the 1 -year RS rate from $87.91 \%$ in 1972 to $90.30 \%$ in 2008-2011, and for the 15-year RS from $45.81 \%$ in 1972 to $48.22 \%$ in $1993-1997$.

\section{Discussion}

This study provides survival estimates of female patients diagnosed with breast cancer in Qidong, China from 1972 through 2011. We compare the results available from other countries or areas. For example, reports from Korea, Japan, United States, and Germany have shown better relative survival rates of female breast cancer than observed in Qidong. The 5-year RS rate $(63.12 \%$ in 1972-2011) of female breast cancer in Qidong was lower than those in Korea $(79.6 \%$ in $1993-1997,85.0 \%$ in 1998-2002) [19], Japan (84.6\% in 1993-1996) [20], United States (89.0\% in 1996-2002) [21], Germany (80.6\% in 2000-2002) [22], and most of other Asia cities 


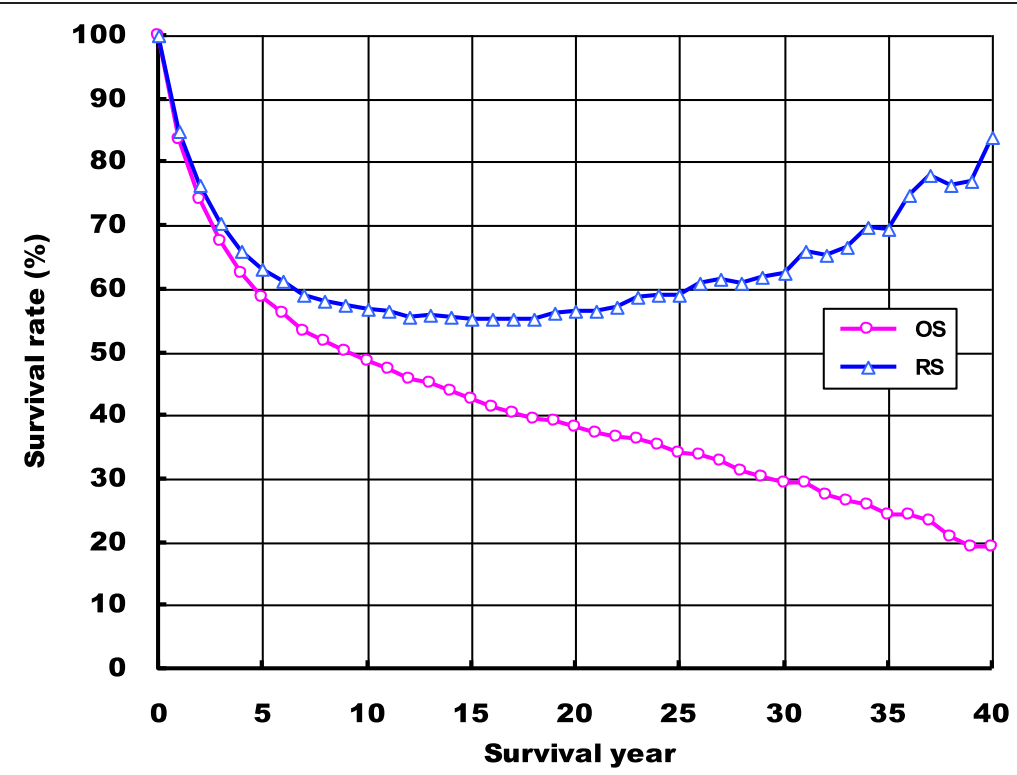

Figure 1 Trends for the observed survival (OS) and relative survival (RS) rates of female breast cancer in Qidong, China, 1972-2011. $\left(-\mathrm{O}^{-}\right)$OS; $\left(-\Delta^{-}\right) \mathrm{RS}$.

or areas $(58.6 \%-88.2 \%$ in 1999) [23], but higher than that of Kampala, Uganda (45.4\% in 1993-1997) [24], and Mumbai, India (46.2\% in 1992-1994) [25]. As Bradley et al. [26] have reported, there are disparities in cancer survival between subjects enrolled in Medicaid and subjects not enrolled in Medicaid, a health insurance program in the United States. Verdecchia et al. [27] indicated that the most direct way for poorer European countries to improve all-cancer survival would be to get richer; for richer countries investment in health technology is important. Hayat et al. [21] suggested these disparities may reflect variations in the prevalence of risk factors, the use of screening tests for early detection, access to health care services, and/or social and demographic factors. In a comparative study of Stockholm and Singapore women with breast cancer, there appear to be differences in the 5-year OS rates of $72 \%$ vs. $64 \%$, and 5-year RS rates of $80 \%$ vs. $70 \%$, respectively. In Qidong, the data highlight an improvement in prognosis over the calendar periods, which were likely influenced by marked economic improvement leading to better medical

Table 2 Five and ten year OS and RS rates of female breast cancer by age-group in Qidong, 1972-2011 (\%)

\begin{tabular}{lllllllll}
\hline \multicolumn{1}{l|}{ Age group } & $\mathbf{1 5 - 3 4}$ & $\mathbf{3 5 - 4 4}$ & $\mathbf{4 5 - 5 4}$ & $\mathbf{5 5 - 6 4}$ & $\mathbf{6 5 - 7 4}$ & $\mathbf{7 5 +}$ & Total \\
\hline 5-year & OS & 59.81 & 67.42 & 66.26 & 53.44 & 47.82 & 30.42 & 58.75 \\
& RS & 60.17 & 68.27 & 67.79 & 56.03 & 55.50 & 55.28 & 63.12 \\
10-year & OS & 53.36 & 57.82 & 58.09 & 42.11 & 32.05 & 14.78 & 48.56 \\
& RS & 54.16 & 59.59 & 61.34 & 47.78 & 51.30 & 59.28 & 56.81
\end{tabular}

OS, Observed survival; RS, Relative survival. facilities and management of patients from diagnosis through treatment, as well as improved treatment options [28]. At the molecular level, Guo et al. [29] reported that the 5-year survival in female patients with ER $\alpha$ (estrogen receptor $\alpha+$ ) is higher than that with ER $\alpha(-)$ in Chinese women.

But no matter how poor the survival shown in this series, compared to results from other parts of the world or from big cities in China, the data indicate that survival rates for breast cancer patients over this 40 year period in Qidong have been improving. Significant upward trends for the 5-year RS rate were observed, increasing from $52.08 \%$ in 1972 to $69.26 \%$ in $2003-2007$, and the 10 -year RS rates from $43.16 \%$ in 1972 to $60.85 \%$ in 1998-2002. The improvement in survival rate between 1972 and 2011 may be attributed to social and economic development, as well as improvement in early detection, such as by increasing the use of mammography, and therapy [30]. Patients also received better quality care, as shown in a pay-for-performance program for breast cancer care in Taiwan [31]. Last century, however, breast cancer screening programs were almost nonexistent in Qidong. It seems reasonable to assume that many of these patients had no chance to receive early detection for the diagnosis of this cancer, and hence, effective treatment was rarely possible. In recently years, screening as well as substantive improvements in diagnosis and treatment have become possible, through which breast cancers could be detected at earlier stages and perhaps more suitable treatment options could be obtained, in turn resulting in improvements in prognosis. 
Table 3 Relative survival rate of female breast cancer by period in Qidong, 1972-2011 (\%)

\begin{tabular}{|c|c|c|c|c|c|c|c|c|c|}
\hline Survival year & 1972 & 1973-1977 & 1978-1982 & 1983-1987 & 1988-1992 & 1993-1997 & 1998-2002 & 2003-2007 & 2008-2011 \\
\hline 1 & 87.91 & 85.54 & 83.28 & 84.38 & 85.77 & 77.02 & 82.90 & 85.19 & 90.30 \\
\hline 2 & 73.74 & 73.66 & 72.86 & 73.98 & 73.73 & 69.92 & 74.30 & 79.47 & 85.06 \\
\hline 3 & 64.39 & 63.54 & 66.27 & 68.35 & 67.92 & 63.17 & 68.72 & 75.89 & 81.55 \\
\hline 4 & 58.35 & 58.85 & 62.71 & 61.85 & 62.57 & 58.51 & 65.18 & 73.06 & 75.71 \\
\hline 5 & 52.08 & 56.30 & 60.43 & 59.98 & 60.32 & 54.62 & 63.11 & 69.26 & - \\
\hline 6 & 52.90 & 54.16 & 59.07 & 58.09 & 57.16 & 52.64 & 61.68 & 67.44 & \\
\hline 7 & 48.15 & 51.51 & 56.24 & 55.79 & 54.53 & 51.15 & 60.49 & 65.70 & \\
\hline 8 & 47.05 & 49.72 & 52.37 & 55.24 & 53.99 & 50.82 & 61.16 & 64.38 & \\
\hline 9 & 44.17 & 49.89 & 50.33 & 52.50 & 54.08 & 50.47 & 61.45 & 65.27 & \\
\hline 10 & 43.16 & 51.13 & 50.24 & 50.82 & 52.92 & 49.76 & 60.85 & - & \\
\hline 11 & 43.99 & 51.93 & 50.14 & 50.62 & 52.41 & 48.70 & 60.46 & & \\
\hline 12 & 44.93 & 49.55 & 51.10 & 48.86 & 51.84 & 48.32 & 59.38 & & \\
\hline 13 & 45.87 & 49.81 & 51.02 & 48.63 & 52.23 & 48.97 & 60.30 & & \\
\hline 14 & 44.79 & 50.03 & 49.88 & 48.01 & 51.93 & 48.67 & 61.22 & & \\
\hline 15 & 45.81 & 49.04 & 50.97 & 47.83 & 51.25 & 48.22 & - & & \\
\hline 16 & 44.67 & 46.78 & 49.83 & 48.10 & 52.35 & 48.82 & & & \\
\hline 17 & 45.82 & 46.86 & 49.85 & 47.91 & 52.81 & 47.47 & & & \\
\hline 18 & 47.05 & 45.02 & 49.28 & 48.11 & 53.74 & 48.77 & & & \\
\hline 19 & 45.76 & 46.38 & 50.60 & 48.80 & 54.77 & 50.05 & & & \\
\hline 20 & 42.02 & 45.83 & 50.77 & 49.04 & 55.89 & - & & & \\
\hline 21 & 43.31 & 43.18 & 51.66 & 49.30 & 57.65 & & & & \\
\hline 22 & 44.70 & 41.10 & 53.21 & 50.15 & 59.66 & & & & \\
\hline 23 & 43.43 & 42.62 & 54.17 & 51.62 & 62.06 & & & & \\
\hline 24 & 42.07 & 41.20 & 55.22 & 52.19 & 64.92 & & & & \\
\hline 25 & 40.72 & 42.18 & 54.83 & 52.69 & - & & & & \\
\hline 26 & 39.31 & 44.10 & 56.66 & 53.66 & & & & & \\
\hline 27 & 37.86 & 44.40 & 57.18 & 55.70 & & & & & \\
\hline 28 & 36.23 & 45.61 & 55.41 & 54.98 & & & & & \\
\hline 29 & 38.07 & 44.93 & 56.99 & 57.12 & & & & & \\
\hline 30 & 32.84 & 46.17 & 58.68 & - & & & & & \\
\hline 31 & 34.71 & 48.56 & 61.57 & & & & & & \\
\hline 32 & 36.29 & 46.81 & 62.74 & & & & & & \\
\hline 33 & 38.08 & 47.39 & 63.33 & & & & & & \\
\hline 34 & 40.38 & 49.38 & 67.23 & & & & & & \\
\hline 35 & 38.06 & 49.98 & - & & & & & & \\
\hline 36 & 40.61 & 53.91 & & & & & & & \\
\hline 37 & 43.89 & 55.24 & & & & & & & \\
\hline 38 & 47.55 & 50.61 & & & & & & & \\
\hline 39 & 51.98 & 43.96 & & & & & & & \\
\hline 40 & 56.78 & - & & & & & & & \\
\hline
\end{tabular}

Our 40 -year results indicate that $58.75 \%(2 * \mathrm{SE}: 1.81 \%)$ of female patients with breast cancer survived 5 years or more, with a 5 -year RS rate of $63.12 \%(2 * \mathrm{SE}: 1.95 \%)$. Statistical differences were noted among the different age groups. Higher 5-, 10-year RS rates were observed from the groups of age 35-54 years in our series, which is consistent with a report from a rural area in China by Chen and his colleagues [32]. Ballard-Barbash 
et al. [33] in a recent systematic review concludes that physical activity is associated with a reduction in breast cancer-specific mortality as well as all-cause mortality; and there is evidence for a dose-response effect of decreasing mortality risk with increasing activity in roughly half of the 27 reported observational studies. This association may be one of the reasons that younger patients had better survival in our series. Besides a variety of known factors including tumor size, nodal status and grade, histological type, improved treatment modalities and screening, and racial differences [34,35], there may be other factors that affect the prognosis of breast cancer, although their mechanisms are unclear. In a meta-analysis which included 43 studies of women diagnosed with breast cancer between 1963 and 2005, Protani et al. [36] illustrated that women with breast cancer who were obese, had poorer survival than women with breast cancer who were not obese, with a HR of 1.33 (95\% CI: 1.21-1.47). Some suggest [37] that weight management is a key to controlling prevalent co-morbid conditions in breast cancer patients, although it is currently unknown whether post-diagnosis weight loss can improve prognosis and disease-free survival.

Stage is often considered to be the most important factor determining survival [28]. Hayat et al. [21] reported that the 5-year relative survival for those diagnosed at early stage (stage I) is very good ( $100 \%$ for all races combined), but if metastatic disease is diagnosed (stage IV), survival drops to $21 \%$ for all races combined. A study in a Finnish population comparing screening-detected and non-screening-detected breast cancer found that breast cancer detected by mammography screening is an independent prognostic factor in breast cancer that is associated with a more favorable survival rate: a 15 -year survival of $86 \%$ for patients screening-detected $v$ s. $68 \%$ for patients diagnosed by other methods [38]. Unfortunately, for our population-based cancer registration series, one limitation of our study was that stage information was available sporadically, a common problem in populationbased cancer registries worldwide [39]. This limitation does not hinder the assessment of the general evolution of better survival from breast cancer in this area. We believe, as the literature [35] has suggested, that disparities in access and quality of care may be eliminated by understanding and addressing cultural and economic barriers.

\section{Conclusions}

The survival outcomes in women with breast cancer in Qidong, China have shown gradual progress during the past 40 years. There remain disparities of survival rates of female breast cancer comparing Qidong to more developed regions, yet the gaps are getting narrower, and there is continuing opportunity for improving breast cancer survival in Qidong.

\section{Abbreviations}

APC: Annual percentage change; Cl: Confidence interval; Cl5: Cancer incidence in five continents; DCN: Death certification notifications; DCO: Death certificate only; ERa: Estrogen receptor a; IACR: International Association of Cancer Registries; IARC: International Agency for Research on Cancer; ICD-10: International Classification of Diseases, the 10th revision; OS: Observed survival rate; QCR: Qidong Cancer Registry; QDLCl: Qidong Liver Cancer Institute; RS: Relative survival rate; 2*SE: Twice standard error; $2^{*} \mathrm{SE}_{\mathrm{O}}$ : Twice standard error of observed survival rate; $2 * \mathrm{SE}_{\mathrm{RS}}$ : Twice standard error of relative survival rate.

\section{Competing interests}

The authors declare that they have no competing interests.

\section{Authors' contributions}

All authors participated in the collection of the data. ZJ carried out the data analyses and interpretation under supervision of CJG. ZJ wrote the first draft of the manuscript. CJG reviewed the data analyses and edited the draft. All authors participated in the revision of the manuscript and approved the final form.

\section{Acknowledgements}

We thank the staff of the 12 towns in Qidong for undertaking the case-finding and follow-up. We thank Prof. Thomas W. Kensler for his useful comments and language editing. This work was supported by Qidong Cancer Registry which collects the data reported by the health workers in the Qidong Health Care System, and was partially supported by the special funds of the Ministry of Finance and the Ministry of Public Health of China: Tumor Follow-up Registration Programs (MF2008-293, 2009-193, and 2010-90).

Received: 20 November 2013 Accepted: 28 April 2014 Published: 6 May 2014

\section{References}

1. Jemal A, Bray F, Center MM, Ferlay J, Ward E, Forman D: Global cancer statistics. CA Cancer J Clin 2011, 61:69-90.

2. Ferlay J, Shin HR, Bray F, Forman D, Mathers C, Parkin DM: Estimates of worldwide burden of cancer in 2008: GLOBOCAN 2008. Int J Cancer 2010, 127:2893-2917.

3. Ziegler RG, Anderson WF, Gail MH: Increasing breast cancer incidence in China: the numbers add up. J Natl Cancer Inst 2008, 100:1339-1341.

4. Chen JG: Cancer in Qidong, China 1972-2011. Beijing: Military Medical Science Press; 2013:1-346.

5. Wei KR, Chen WQ, Zhang SW, Liang ZH, Zheng RS, Ou ZX: Cancer registration in the Peoples Republic of China. Asian Pac J Cancer Prev 2012, 13:4209-4214.

6. Chen W, Armstrong BK, Zheng R, Zhang S, Yu X, Clements M: Cancer burden in China: a Bayesian approach. BMC Cancer 2013, 13:458.

7. Chen JG, Peto R, Sun ZT, Zhu YR: Feasibility of a prospective study of smoking and mortality in Qidong, China. In Relevance to Human Cancer of N-Nitroso Compounds, Tobacco and Mycotoxins. Edited by O'neill IK, Chen J, Bartsch H. Lyon: IARC Sci Publ No. 105; 1991:502-506.

8. Parkin DM, Whelan SL, Ferlay J, Raymond L, Young J: Cancer Incidence in Five Continents, Vol VII. Lyon: IARC Sci Publ No. 143; 1997.

9. Parkin DM, Whelan SL, Ferlay J, Storm H: Cancer Incidence in Five Continents Vol. VIII. Lyon: IARC Sci Publ No. 155; 2002.

10. Chen JG, Li WG, Shen ZC, Yao HY, Zhang BC, Zhu RY: Population-based cancer survival in Qidong, China. In Cancer Survival in Developing countries. Edited by Sankaranarayanan R, Black R, Parkin DM. Lyon: IARC; 1998:27-35.

11. Chen JG, Zhu J, Parkin DM, Zhang YH, Lu JH, Zhu YR, Chen TY: Trends in the incidence of cancer in Qidong, China, 1978-2002. Int J Cancer 2006, 119:1447-1454.

12. Chen JG, Zhu J, Zhang YH, Lu JH: Cancer survival in Qidong, China, 1992-2000. In Cancer Survival in Africa, Asia, the Caribbean and Central America. Edited by Sankaranarayanan R, Swaminathan R. Lyon: IARC Sci Publ No. 162; 2011:43-53.

13. Ferlay J, Soerjomataram I, Ervik M, Dikshit R, Eser S, Mathers C, Rebelo M, Parkin DM, Forman D, Bray F: GLOBOCAN 2012 v1.0, Cancer Incidence and Mortality Worldwide: IARC CancerBase No. 11 [Internet]. Lyon, France: International Agency for Research on Cancer; 2013. Available from: http://globocan.iarc.fr. 
14. Zhao P, Chen WQ, Kong LZ: Cancer incidence and mortality in China (2003-2007). Beijing: Military Medical Science Press; 2012.

15. Fritz A, Percy C, Jack A: International Classification of Diseases for Oncology. 3rd edition. Geneva: World Health Organization; 2000.

16. Hakulinen T: Cancer survival corrected for heterogeneity in patient withdrawal. Biometrics 1982, 38:933-942.

17. Parkin DM, Hakulinen T: Analysis of survival. In Cancer registration: principles and methods. Edited by Jensen OM, Parkin DM, Maclennan R, Muir CS, Skeet RG. Lyon: IARC Sci Publ No. 95; 1991:159-176.

18. Finnish Cancer Registry: SURV3: Windows Software for Relative Survival Analysis. http://www.cancer.fi/@Bin/54321472/index.html.

19. Jung KW, Yim SH, Kong HJ, Hwang SY, Won YJ, Lee JK, Shin HR: Cancer survival in Korea 1993-2002: a population-based study. J Korean Med Sci 2007, 22(Suppl):5-10.

20. Tsukuma H, Ajiki W, loka A, Oshima A: Survival of cancer patients diagnosed between 1993 and 1996: a collaborative study of population-based cancer registries in Japan. Jpn J Clin Oncol 2006, 36:602-607.

21. Hayat MJ, Howlader N, Reichman ME, Edwards BK: Cancer statistics, trends, and multiple primary cancer analyses from the Surveillance, Epidemiology, and End Results (SEER) program. Oncologist 2007, 12:20-37.

22. Brenner $\mathrm{H}$, Stegmaier $\mathrm{C}$, Ziegler $\mathrm{H}$ : Long-term survival of cancer patients in Germany achieved by the beginning of the third millenium. Ann Oncologist 2005, 16:981-986.

23. Tanaka H, Tanaka M, Chen W, Park S, Jung KW, Chiang CJ, Lai MS, MirasolLumague MR, Laudico AS, Sinuraya ES, Nishino Y, Shibata A, Fujita M, Soda M, Naito M, Tsukuma H, Moore MA, Ajiki W: Proposal for a cooperative study on population-based cancer survival in selected registries in East Asia. Asian Pac J Cancer Prev 2009, 10:1191-1198.

24. Gondos A, Brenner H, Wabinga H, Parkin DM: Cancer survival in Kampala, Uganda. Br J Cancer 2005, 92:1808-1812.

25. Yeole BB, Kumar AV, Kurkure A, Sunny L: Population-based survival from cancers of breast, cervix and ovary in women in Mumbai, India. Asian Pac J Cancer Prev 2004, 5:308-315.

26. Bradley CJ, Gardiner J, Given CW, Roberts C: Cancer, medicaid enrollment and survival disparities. Cancer 2005, 103:1712-1718.

27. Verdecchia A, Baili P, Quaglia A, Kunkler I, Ciampichini R, Berrino F, Micheli A: Patient survival for all cancers combined as indicator of cancer control in Europe. Eur J Public Health 2008, 18:527-532.

28. Tan BKT, Lim GH, Czene K, Hall P, Chia KS: Do Asian breast cancer patients have poorer survival than their western counterparts? A comparison between Singapore and Stockholm. Breast Cancer Res 2009, 11:R4.

29. Guo QQ, Lu JP, Zhang YX, Lai QX, Liu Y, Liu F, He Y: The relationship between estrogen receptor a expression and 5-year survival in Chinese women with breast cancer: a meta analysis. J Chin Oncol 2011, 17:602-607.

30. Gondos A, Bray F, Hakulinen T, Brenner H: Trends in cancer survival in 11 European populations from 1990 to 2009: a model-based analysis. Ann Oncol 2009, 20:564-573.

31. Kuo RN, Chung KP, Lai MS: Effect of the pay-for-performance program for breast cancer care in Taiwan. J Oncol Pract 2011, 7(Suppl 3):8-15.

32. Chen JS, Xiao JR, Chen ZC, Zhang G, Wu JP, Zhou TS: Relative survival rate analysis of cancer patients in Changle city. Chin Cancer 2002, 9:535-536.

33. Ballard-Barbash R, Friedenreich CM, Courneya KS, Siddiqi SM, MCTiernan A, Alfano CM: Physical activity, biomarkers, and disease outcomes in cancer survivors: a systematic review. J Natl Cancer Inst 2012, 104:815-840

34. Soerjomataram I, Louwman MW, Ribot JG, Roukema JA, Coebergh JW: An overview of prognostic factors for long-term survivors of breast cancer. Breast Cancer Res Treat 2008, 107:309-330.

35. Ademuyiwa FO, Edge SB, Erwin DO, Orom H, Ambrosone CB, Underwood W 3rd: Breast cancer racial disparities: unanswered questions. Cancer Res 2011, 71:640-644

36. Protani $\mathrm{M}$, Coory M, Martin $\mathrm{JH}$ : Effect of obesity on survival of women with breast cancer: systematic review and meta-analysis. Breast Cancer Res Treat 2010, 123:627-635.

37. Demark-Wahnefried W, Campbell KL, Hayes SC: Weight management and its role in breast cancer rehabilitation. Cancer 2012, 118(Suppl 8):2277-2287.
38. Lehtimäki T, Lundin M, Linder $\mathrm{N}$, Sihto H, Holli $\mathrm{K}$, Turpeenniemi-Hujanen $\mathrm{T}$,

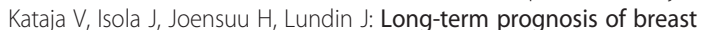
cancer detected by mammography screening or other methods. Breast Cancer Res 2011, 13:R134.

39. Eisemann N, Waldmann A, Katalinic A: Imputation of missing values of tumour stage in population-based cancer registration. BMC Med Res Methodol 2011, 11:129

doi:10.1186/1471-2407-14-318

Cite this article as: Zhu et al:: Female breast cancer survival in Qidong,

China, 1972-2011: a population-based study. BMC Cancer 2014 14:318.

\section{Submit your next manuscript to BioMed Central and take full advantage of:}

- Convenient online submission

- Thorough peer review

- No space constraints or color figure charges

- Immediate publication on acceptance

- Inclusion in PubMed, CAS, Scopus and Google Scholar

- Research which is freely available for redistribution

Submit your manuscript at www.biomedcentral.com/submit
C Biomed Central 